\title{
O CASO PILA: criatividade, inovação e organização para resultados através do design de cultura regional.
}

\author{
Janaina Luisa da Silva Moroni \\ Universidade Federal do Rio Grande do Sul - UFRGS \\ janaina.moroni@ufrgs.br \\ Eliane Rodrigues \\ Instituto de Psicologia de Novo Hamburgo - IPSI \\ elianerd@gmail.com \\ Gloria Maria Leite \\ Universidade Federal do Rio Grande do Sul - UFRGS \\ glorinha22@yahoo.com \\ Jussara Smidt Porto \\ Universidade Federal do Rio Grande do Sul - UFRGS \\ jussara.porto@ufrgs.br \\ Marcelo Cabeda \\ Universidade Luterana do Brasil - ULBRA \\ marcelo.cabeda@gmail.com
}

Resumo: Este artigo relata o trabalho do Programa Design no Bairro, sobre um estudo aplicado na área de design social, ou seja, uma atividade interdisciplinar. Com a união de profissionais da administração, design, e psicologia foram realizados treinamentos, palestras e oficinas para integrar os jovens moradores de comunidade menos favorecidas, em termos sócio-econômicos, com os jovens estudantes dos cursos de graduação em Design Visual e Design de Produto da UFRGS - Universidade Federal do Rio Grande do Sul, situada na cidade de Porto Alegre, RS, Brasil, com objetivo de intercambiar conhecimentos, favoráveis a todos os participantes, para estimular o estudo e vivenciar a realização de projetos de design social. $O$ estudo ocorreu em uma Organização Não Governamental - ONG - em uma cidade do Rio Grande do Sul, na grande Porto Alegre, capital do estado do Rio Grande do Sul, Brasil. Como resultado, diversos produtos de valorização gaúcha foram criados, mas o que mais se destacou foi o projeto de criação de um novo produto para fixar uma cultura com sabor regional.

Palavras-chave: Design, Criatividade, Inovação, Design Social, Empreendedorismo. 


\begin{abstract}
This paper describes the work of the program Design no Bairro, a study in the field of social design, in other words, an interdisciplinary activity. Putting together management, design e psychology professionals, the study performed training, lectures and workshops in order to socially and economically integrate the low income community's youth with university Visual and Product Design students the UFRGS - Universidade Federal do Rio Grande do Sul, located in the city Porto Alegre, RS, Brazil, seeking knowledge exchange to all the participants, stimulating study and experiencing the accomplish of social design projects. The study was made in a non-governmental organization - ONG - located in the city, in grater Porto Alegre, capital of Rio Grande do Sul State, Brazil. As a result, several gaucho products were created, but the highlight was a project of a product to set a regional flavored culture.
\end{abstract}

Keywords: Design, Creativity, Innovation, Social Design, Entrepreneurship.

\title{
1. INTRODUÇÃO
}

A criatividade, conforme Legrenzi (2005), não pode ser pensada como um contexto sobrenatural ou global, mas sim, concebida como um fenômeno circunscrito em um âmbito específico. Sicklinger (2005) classifica o que denomina criatividade básica como sendo aquela realizada para sobrevivência, ou seja, na falta de criação de um objeto, há a criação de adaptações ou, inclusive, a geração de um novo conceito de produto.

Esse conceito foi basilar para a realização do presente estudo, que teve início em julho de 2013, na ONG (Organização Não-Governamental) "Comitê da Cidadania de Sapucaia do Sul", que atende comunidades carentes de Sapucaia do Sul, município do estado do Rio Grande do Sul. O Programa Design no Bairro buscou potencializar a criatividade básica numa comunidade, carente no aspecto socioeconômico, atendida pela ONG, visando, assim, ampliar a renda familiar das pessoas envolvidas, além de incluir os alunos da graduação de Design Visual e Design de Produto na criação de projetos colaboradores de geração de renda para essas pessoas.

Voltado ao empreendedorismo, o trabalho consistiu no desenvolvimento da criatividade dos jovens carentes, por meio de cursos de serralheria, funilaria e culinária. Para isso, foram empregadas técnicas das áreas de Administração, Design e Psicologia.

Para Drucker (1974), empreendedorismo é prática, visão de mercado, evolução. O autor afirma ainda que o trabalho específico do empreendedorismo, numa empresa de negócios, é fazer com que os negócios de hoje sejam capazes de fazer o futuro, transformando-se em um negócio diferente. Segundo o autor "[...] Empreendedorismo não é nem ciência, nem arte. É uma prática."(DRUKER, 1974, p. 25).

Em todas as etapas, os objetivos da coordenação do Programa Design no Bairro, em relação à comunidade foram: (i) analisar o conhecimento ensinado na ONG; (ii) verificar a estrutura de trabalho de determinada técnica assimilada pela comunidade, (iii) identificar competência e talento dos grupos envolvidos e, (iv) propor treinamentos, palestras e oficinas. Já, em relação aos alunos da graduação, dos cursos de Design Visual e Design de Produto, o foco foi aplicar, na prática, o conteúdo teórico ensinado nas disciplinas. 
Giacobone e Gallico (2010, p. 136), definem quem é capaz de traduzir as visões em produtos e serviços para a sociedade como "designer pensante". O aperfeiçoamento da visão do designer pensante, nesse sentido, possibilita a materialização das soluções, oferecendo melhores resultados ao mercado. Seguindo esse conceito, o presente projeto reforça o objetivo de oportunizar aos alunos da graduação a oportunidade de pensar em produtos que sejam soluções capazes de melhorar a renda de comunidades carentes.

A ideia do presente projeto, portanto, foi estimular e oportunizar a experiência prática de criação de produtos voltados à geração de renda para os alunos da ONG e dos cursos de Design. Dentre todas, a que se destacou foi a criação de um biscoito chamado PILA, cujo resultado será apresentado a seguir.

\section{DESENVOLVIMENTO}

Partindo da concepção de que todo trabalho resulta da reunião de conhecimentos advindos de diversas áreas, neste estudo, as áreas de Administração, Design e Psicologia uniram-se aos saberes técnicos da serralheria, funilaria e da culinária, na busca de soluções para melhorar a renda das pessoas da comunidade participante do projeto.

Associadas à ausência de um produto culinário regional, propôs-se o desafio de criar um novo produto com sabor do Rio Grande do Sul, e, assim, envolver os jovens do curso de padaria e confeitaria com os jovens dos cursos de serralheria e funilaria da ONG "Comitê da Cidadania de Sapucaia do Sul", em conjunto com os alunos da Universidade Federal do Rio Grande do Sul - UFRGS, especificamente, dos cursos de graduação em Design Visual e Design de Produto. O resultado desse desafio foi um biscoito feito à base de erva-mate e farinha de trigo.

Uma das primeiras etapas do projeto consistiu em treinamentos, dos quais participaram os alunos tanto da graduação quanto da ONG.

Estes treinamentos dividiram-se em cinco etapas: (i) apresentação do que é a área de Design, com exemplos de produtos inovadores, onde se estuda design, apresentação dos laboratórios e demais espaços da universidade; (ii) criatividade e empreendedorismo; (iii) criatividade e reaproveitamento de papel para embalagem; (iv) criatividade e psicologia; e (v) design: uso de ferramentas criativas para estimular projetos inovadores.

Como referência, para a metodologia empregada nos treinamentos, foram usados os seguintes autores: Dornelas (2001) e Drucker (1974), da área da administração; Kruchen (2009), do design e território; e De Bono (2000), da área de psicologia.

Segundo Gallico (2010) um processo é um instrumento. Para desfrutar da potencialidade ao máximo, o autor afirma que a escolha da ferramenta deve ser adequada, mas são as pessoas é que fazem a diferença. Logo, não está na habilidade técnica e sim no backgroud cultural.

Nesse sentido, a equipe do Programa realizou uma coleta das ferramentas mais efetivas na potencialidade criativa, para instruir as pessoas com diversas bagagens culturais a selecionar as suas melhores ideias. Assim, elaborou-se o seguinte roteiro para dar continuidade ao trabalho:

- Análise das atividades ensinadas aos jovens da ONG; 
- Entrevistas com os jovens, com os instrutores dos cursos dados na ONG e com o presidente da ONG;

- Levantamento de necessidade de mercado e os conhecimentos dos alunos envolvidos no treinamento;

- Elaboração de palestras e oficinas com os resultados do levantamento de necessidades, participação desta fase com alunos da ONG e universidade;

- Treinamentos, palestras e oficinas a alunos e instrutores da ONG e dos alunos da universidade;

- Treinamento em empreendorismo, design de embalagens recicladas, psicologia e criatividade e ferramentas criativas utilizadas no design para criação e inovação de produtos;

- Acompanhamento das atividades;

- Realização de desenhos sobre as novas ideias geradas na criação de produtos;

- Seleção da melhor idéia - avaliação esta feita em conjunto com os próprios participantes e com os professores;

- Realização de modelos da ideia em formato tridimensional;

- Ajustes e escolha final do produto;

- Realização de Protótipo;

- Realização de moldes para produção em série;

- Ajustes e produção final;

- Levantamento de mercado;

- Levantamento de custo;

- Apresentação do primeiro produto em feiras e espaços de divulgação social.

- Avaliação da aceitação do produto pelo público e sua disposição de pagar pelo mesmo.

\subsection{Criatividade e Empreendedorismo}

O conceito e a compreensão do significado da palavra empreender foi o mote inicial do treinamento. Assim, tem-se que empreender é criar riqueza através de novos produtos para novos mercados, desenvolvendo a economia de uma sociedade.

$O$ termo empreendedorismo tem origem na palavra empreender, que significa realizar, fazer ou executar. Foi na França, por volta dos séculos XVII e XVII, que a expressão "entrepreneur" (empreendedor) surge como designação para pessoas ousadas que estimulavam o processo econômico mediante novas e melhores formas de agir. Houve uma evolução deste conceito quando, no início do século XIX, o economista francês Jean-Baptiste Say conceituou o empreendedor como o indivíduo capaz de mover recursos econômicos de uma área de baixa para outra, de maior produtividade e retorno.

Já no século XX, o austríaco Joseph Shcumpeter, também economista, define o empreendedor como o indivíduo que reforma ou revoluciona o processo "criativodestrutivo" do capitalismo, por meio do desenvolvimento de uma nova tecnologia ou do aprimoramento de uma antiga - o real papel da inovação. Portanto, são estes indivíduos os agentes de mudança numa economia. Peter Ferdinand Drucker, considerado "o pai da administração moderna", veio ampliar a definição proposta por 
Jean-Baptiste Say, descrevendo os empreendedores como aqueles que aproveitam as oportunidades para criar as mudanças.

Com base nesses conceitos, o presente trabalho buscou desenvolver um pensamento de empreendedorismo nos jovens envolvidos que, partindo do conhecimento dos produtos da região do Rio Grande do Sul, como reconhecidamente tradicionais, os levassem à criação de um produto que se identificasse imediatamente com o local de sua fabricação. Logo, o processo foi dividido em duas etapas. A primeira, centrou-se no empreendedorismo, nos conceitos e no cálculo de valores de criação de novos produtos. A segunda, ocupou-se com os planejamentos futuros e a visualização de cálculos, baseando-se na técnica SMART.

\subsubsection{Treinamento e oficina de empreendedorismo}

O projeto teve início, conforme já mencionado, com a fase de treinamento, ministrado pela administradora Gloria Maria Leite, que envolveu todos os participantes.

Nesta fase, foram realizados dois momentos de imersão onde pequenos grupos discutiram acerca de produtos que poderiam representar o Rio Grande do Sul, e, a posteriori, mostraram seus produtos para o grande grupo. (Figura 1)

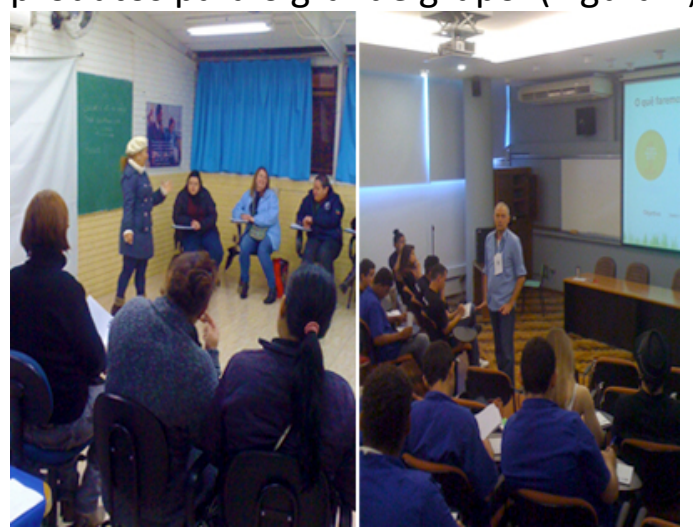

Figura 1 - Treinamento em Empreendedorismo e SMART pelos administradores Gloria Maria Leite e Marcelo Cabeda.

Fonte: Elaborado pelos autores, com base na pesquisa realizada.

Num segundo momento, fortificou-se a elaboração de um estudo preliminar de implantação de um novo produto, através de um rápido planejamento de mercado, cujas variáveis principais eram produto $x$ população. Neste ponto, conceitos de planejamento e a administração se fizeram necessários. Em relação a isso, Dornelas (2001) afirma que o empreendedor se torna um administrador completo, uma vez que incorpora as várias abordagens existentes, sem se restringir a apenas uma delas, interagindo com seu ambiente para, assim, tomar as melhores decisões.

\subsubsection{Treinamento e oficina técnica SMART}

Durante o evento, voltado ao desenvolvimento das Características de Comportamento Empreendedor, ministrado pelo engenheiro e administrador Marcelo Cabeda, optou-se na aplicação da técnica SMART para a definição de metas mais completas. Segundo a bibliografia, não há muitas referências acerca da origem desta técnica, sendo que os registros mais antigos datam de 1981, em livros de George Doran. Tem-se que o termo SMART vem do inglês e significa "esperto". A palavra é usada como uma sigla de fácil memorização para os itens imprescindíveis na definição 
de objetivos, e esta técnica é usada hoje pela maioria das grandes empresas. Nesse sentido, conforme Medeiros (2014), a meta deve:

- $\quad$ Ser ESPECÍFICA - do inglês Specific - "Conseguir vender o novo produto PILA" remete ao ponto inicial de necessidade de divulgação entre conhecidos e vizinhança, mas "conseguir um bom espaço de divulgação em feiras com um ganho superior de, pelo menos, $\mathrm{R} \$ \mathbf{8 . 0 0 0 , 0 0}$ por mês", mostra exatamente aonde se quer chegar.

- Ser MENSURÁVEL - do inglês Measurable - é importante para determinar quando o objetivo traçado é alcançado. Ou seja, o objetivo deve ter uma medida. Para exemplificar, no caso deste projeto, pode-se definir como medida o alto rendimento e franquias que vendam o produto "PILA".

- $\quad$ Ser ATINGÍVEL - do inglês Attainable - Objetivos inalcançáveis não viram realidade. Ressalta-se a necessidade de sonhar No caso do produto PILA, esse conceito pode ser explicado segundo o raciocínio: "aplicar energia e força de vontade para ser aprovado no aluguel de uma loja, de um shopping luxuoso, como primeiro passo da empresa, sem antes planejar se existem, de fato, rendimentos para alugá-lo" pode não ser objetivo alcançável.

- Ser RELEVANTE - do inglês Relevant - Ouseja, "fazer sentido". Conforme Medeiros (2014), quando criamos a própria meta, é mais fácil que ela faça sentido, pois tendemos a escolher aquilo que nos interessa. Entretanto, pode acontecer de não percebermos a direção de um caminho errado. Por exemplo, de que valeria estudar decoração de bolos se o produto PILA não requer esta habilidade? Portanto, os investimentos, tanto financeiros quanto em formação, sempre devem ser importantes para a realização do produto em questão.

- $\quad$ Ser TEMPORAL - do ingles Time-bound - Conforme o autor, nosso cérebro não reconhece a urgência de uma atividade, até saber quando ela deve ser completada. Portanto, para saber se o projeto está indo bem, é preciso estabelecer metas para a realização do objetivo principal, as quais devem ser cumpridas em determinado prazo. $O$ ato de aprender um nova receita, por exemplo, pode ser dividido em: (i) procurar e escolher uma receita, com o prazo de 1 semana; (ii) assistir todos os dias aulas de culinária, com o prazo de 6 meses letivos; (iii) começar a comprar revistas de receitas, com prazo de 4 meses; estabelecendo, assim, "marcos" (milestones) que permitirão a autoavaliação e a análise do progresso individual. Logo, sugere-se definir prazos para o objetivo final, com base nas pequenas metas, tornando-o mais "palpável".

\subsection{Criatividade e reaproveitamento de papel para embalagens}

Pensando no desenvolvimento da embalagem para o produto PILA, empregouse a ferramenta de metodologia denominada HCD "Procurando inspiração em novos lugares". Os facilitadores se valeram do apoio da pesquisa Blue Sky, baseada nos estudos de Celso Carlos Scaletsky e Fábio Pezzi Parode (2008), para apresentar as possibilidades existentes e ajudar na construção de conceitos e na criação de ideias que fossem pertinentes para o desenvolvimento das embalagens que seriam propostas.

Durante uma oficina, ministrada pela designer Jussara Smidt Porto, diretora da Gráfica da UFRGS e coordenadora do Núcleo de Desenvolvimento de Reaproveitamento de Papel, em conjunto com bolsistas que possuem um grupo que 
desenvolve produtos a partir do resíduo de papel gerado na Gráfica da UFRGS, uma série de slides foram apresentados, com um número significativo de embalagens (já produzidas ou em processo de produção), para criar referências às pessoas que iriam produzi-las. Após, foi solicitado que, através de um exercício se criasse uma embalagem para o PILA. A experiência foi realizada e vários protótipos foram desenvolvidos. (Figura 2).

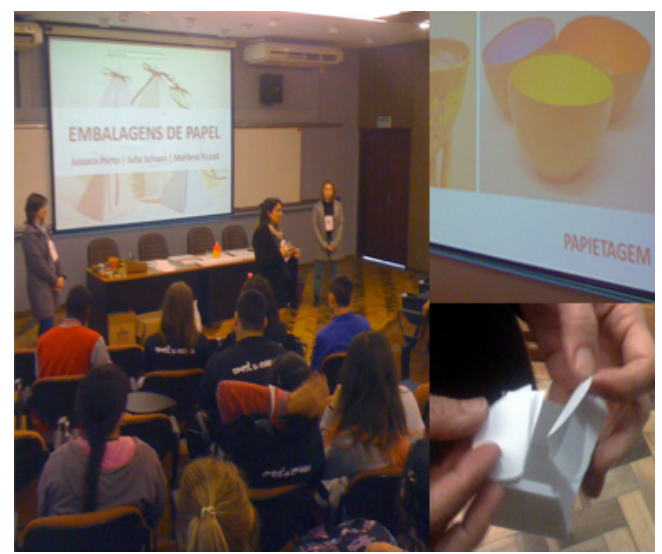

Figura 2 - Treinamento em embalagem de papel ministrado pela designer Jussara Smidt Porto. À direita, embalagem criada pela comunidade.

Fonte: Elaborado pelos autores, com base na pesquisa realizada.

\subsection{Criatividade e Psicologia}

Existem muitos fatores e crenças pessoais que limitam a expressão da criatividade, tais como o conformismo, o autoritarismo, a intolerância pelo o que é diferente daquilo que lhe é conhecido, e, talvez a mais importante, a dificuldade em pensar livremente. Para Chuster \& Cols (2011) é preciso aprender a pensar a partir da experiência, bem como acolher o inesperado, surpreender-se com o estranho, o novo e o desconhecido

Nesse sentido, a criatividade faz parte da natureza humana e irá se desenvolver em maior ou menor grau, dependendo das condições ambientais e sociais.

A possibilidade de criar está ligada ao contexto histórico, familiar, escolar e à riqueza de experiências vivenciadas pela criança. $E$, como atividade humana, é semioticamente mediada pela cultura (MOZZER \& BORGES, 2008).

Sabe-se que o indivíduo é uma pessoa original. Seu comportamento caracteriza-se pela excepcionalidade oriunda de uma história idiossincrática. Sendo assim, formar indivíduos é formar pessoas criativas, é educar para a criatividade. À grosso modo, uma educação para a criatividade deve reconhecer a importância da diversidade e tirar a ênfase da reprodução. Isso significa planejar condições de aprendizagem que aumentem a probabilidade da ocorrência de comportamentos originais, estimulando os acidentes e os "erros" e os "desvios" e as novidades com origem no comportamento do indivíduo (MURARI \& HENKLAIN, 2013)

Logo, é possível afirmar que a capacidade criativa pode ser estimulada, porém, seu desenvolvimento depende de diferentes variáveis, tais como: (I) as variáveis cognitivas - inteligência, conhecimento e habilidades técnicas; (II) as variáveis ambientais - fatores político-religiosos, culturais, socioeconômicos e educacionais; e também (III) as variáveis de personalidade, através da motivação, da confiança, do não-conformismo e da criatividade como traço subjetivo (EYSENCK, 1999). 
Para colocar em prática o que foi apresentado em relação à teoria e à colaboração da psicologia para o desenvolvimento do novo produto PILA, realizou-se uma oficina, com a psicóloga Eliane Rodrigues. Para iniciá-la, foi solicitado que os participantes desenhassem uma pessoa e nelas escrevessem o que era solicitado (Figura 3).

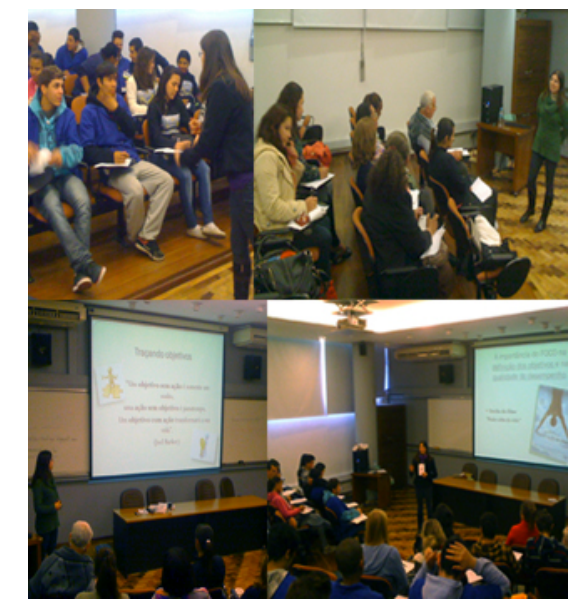

Figura 3 - Oficina Criatividade, Foco e Persistência ministrada pela psicóloga Eliane Rodriguez. Fonte: Elaborado pelos autores, com base na pesquisa realizada.

Solicitou-se aos participantes que, na cabeça, escrevessem seus principais sonhos e crenças; nos braços, os recursos necessários para a construção do sonho; e, nas pernas e pés, os passos a serem dados para a realização dos mesmos.

Na sequência, os participantes foram convidados a fazerem um esboço de um projeto, com base em algum sonho ou objetivo de vida específico, atentando para a importância de fazerem um planejamento viável e consciente, para que a realização deste se tornasse possível.

Para abordar o tema "Foco", foi exibida uma cena do filme "Poder além da vida". O objetivo principal foi o de refletir sobre a importância do foco na definição dos objetivos e na qualidade do desempenho das tarefas a serem cumpridas. O tema "Persistência" foi debatido a partir de trechos do filme "De porta em porta", onde se buscou refletir que toda a meta possui desafios, situações difíceis, quase impossíveis de serem vencidas, mas que a persistência é necessária para a superação.

\subsection{Design: uso de ferramentas criativas para estimular projetos inovadores}

Visando aumentar o repertório visual e de conhecimento dos participantes, foi apresentado um trabalho elaborado pelo designer italiano, da área alimentícia, Paolo Ulian, ganhador do prêmio criativo, o qual consiste em uma bolacha em formato de dedo, espécie de dedal comestível, usado para poder raspar o fundo do pote do doce de chocolate com creme de amêndoas, da empresa Nutella.

Após esta apresentação, realizou-se o treinamento, ministrado pela designer Janaina Luisa da Silva Moroni, que foi baseado nos seus próprios resultados aplicados em estudos de 2009 até 2013, com 36 técnicas criativas utilizadas em projetos de design, dentre as quais os alunos selecionaram as quatro técnicas mais efetivas no seu processo criativo: (i) brainstorm visual; (ii) analogia; (iii) pensamento lateral; seis chapéus e (iv) MESCRAI. As mesmas estão brevemente descritas abaixo.

Segundo Baxter (2000), na primeira técnica, de Brainstorm Visual, também denominada de painel semântico, os participantes devem combinar imagens com a 
expressão não-verbal através do uso de painéis. A segunda técnica, de Analogia, consiste em transferir características de um objeto para outro, com objetivo de criar um novo. Já a terceira técnica, de pensamento lateral, cuja autoria é de De Bono (2000), que a nomeou de Seis Chapéus, facilita a análise crítica do projeto mediante o uso de chapéus coloridos. Cada cor representa um comportamento e este deve ser incorporado para gerar opiniões sobre projetos de inovação. Depois, utilizou-se a técnica MESCRAI, desenvolvida por Orborn, em 1953, e ampliada por Baxter (2000). Esta é a quarta técnica, onde cada letra traz uma ação, "M" (modificar), "E" (eliminar), "S" (substituir), "C" (combinar), "R" (readaptar), " $A$ " (adaptar), "I" (inverter).

A figura 4 apresenta as reuniões, com alunos e técnicos, da ONG, Comitê da Cidadania de Sapucaia do Sul, e da UFRGS, aplicando as técnicas criativas para produzir novos produtos baseados na cultura gaúcha.

Os conceitos de Design visual e Design de Produto foram aliados aos conhecimentos da funilaria, serrilharia, confeitaria e padaria para produzir o logo, as embalagens, a forma do biscoito e gravação da marca no mesmo.

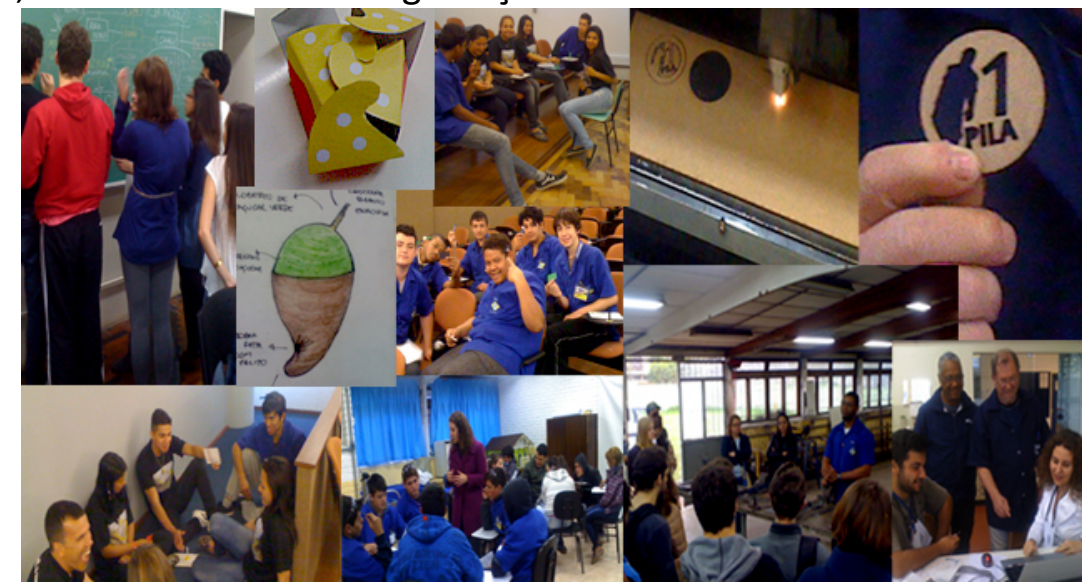

Figura 4 - Alunos, técnicos da ONG e da Universidade aplicando as técnicas criativas e produzindo modelos/protótipos de embalagens e molde para relevo da massa de biscoito.

Fonte: Elaborado pelos autores, com base na pesquisa realizada.

\section{CONCLUSÃO}

Obteve-se a criação de alguns produtos que, ou não eram de fácil comercialização, ou não tinham uma expressão culturalmente identificável no mercado brasileiro. Finalmente, foi na turma da padaria da ONG "Comitê da Cidadania de Sapucaia do Sul" que surgiu um produto que poderia bem identificar o Rio Grande do Sul: a criação de um biscoito doce chamado "Pila". A expressão "pila" é uma palavra regional gaúcha que dá nome à moeda nacional brasileira, no caso o Real. Ou ainda, para um gaúcho um "pila" tem o mesmo valor de um Real, segundo encontramos no Dicionário de Regionalismos do Rio Grande do Sul, de Zeno e Nunes (2009), editado por Martins Livreiro.

O produto atende às necessidades levantadas: valor comercial aceitável, demanda que atingisse, não somente a população do estado do Rio Grande do Sul, como também as demais regiões do país e, talvez, até do exterior, uma vez que é um produto de fácil embalagem, de boa conservação, um sabor diferenciado e que atingiria aos mais variados públicos, independente de idade, gênero, posição social, enfim, um produto que atende às variáveis ideais de custo $\mathrm{x}$ benefício.

$\mathrm{O}$ biscoito criado consiste em duas partes redondas feitas de uma massa à base de farinha de trigo e erva mate - folha macerada de uma árvore da família das 
equifoliáceas, originária da região subtropical da América do Sul e consumida como chá quente no Rio Grande do Sul através do "chimarrão", bebida quente, característica dessa região, de cor verde escuro, o que proporciona à massa uma cor verde claro, um sabor que identifica imediatamente a erva mate - chimarrão - e tem um recheio de doce de leite, igualmente comum em nossa região do pampa.

Foram feitas algumas receitas até que se chegasse ao ponto ideal de consistência e, na apresentação, há um baixo relevo com a expressão "1 Pila". Na figura 4, pode-se visualizar a produção do estudo do primeiro molde em madeira, para executar o molde final do relevo na serralheria e funilaria. Nesta etapa, mesclaram-se os conhecimentos dos técnicos da ONG - Comitê da Cidadania de Sapucaia do Sul, com os técnicos da Universidade - UFRGS.

Originariamente, o produto seria elaborado exclusivamente pela padaria, mas, por ser um trabalho conjunto e que obteve total aceitação de todos os participantes, as fôrmas de metal e o carimbo foram feitas pela funilaria, e a escrita e identificação do produto (1 Pila) foi elaborado pelos alunos da serralheria. Portanto, o produto envolveu, em sua criação, todos os cursos da referida ONG.

Desenvolvido o produto, realizou-se uma exposição na Faculdade de Arquitetura da Universidade, com outros produtos procedentes do mesmo treinamento, mas, inegavelmente, foi o "1 Pila" o que mais se popularizou. A figura 5 mostra o resultado final da embalagem criada para o novo produto PILA inspirada na tradição gaúcha.

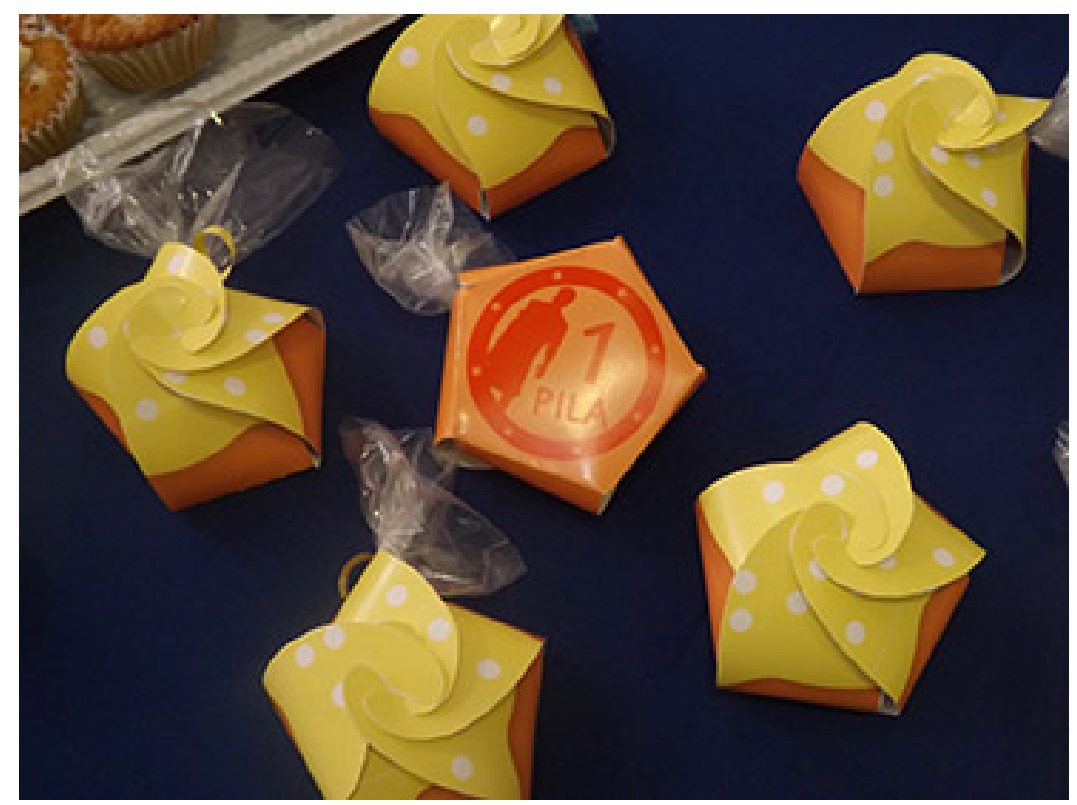

Figura 5 - Embalagem final do novo produto PILA - parceria de ideias da comunidade da ONG e da universidade. Design de embalagem de Odair Santos. Design do logo Marta Zimmermann.

Fonte: Elaborada pela presidente da ONG, Nara Morais, durante evento de apresentação dos resultados deste trabalho.

\section{AGRADECIMENTOS}

Os autores agradecem a ONG Comitê da Cidadania de Sapucaia do Sul, Felipe Leonardo da Rocha Sabala, Mauricio Fernando de Oliveira Jesuíno, Nara Morais, Raquel Morais, Leonídio da Padaria e Confeitaria e demais integrantes, aos técnicos da maquetaria UFRGS, Sr. Leonel e assistente, aos alunos da UFRGS, Bruno Cardoso, Bruno Assis Silva, Fernando Ferreira, Luciana Oliveira Gonçalves, Maria Victoria Pasini, 
Marta Zimmermann, Odair Santos e Tainá Silva Cardeal, aos apoiadores e colaboradores Profa Diretora da Fac. Arquitetura Maria Cristina Dias Lay, Prof. Airton Cattani e Profa Maria do Carmo Curtis, a Profa e Diretora da Extensão UFRGS, Sandra de Deus e suas assistentes, ao Chefe do Departamento de Design e Expressão Gráfica Prof. Paulo Edi Rivero Martins que assumiu a coordenação do Programa Design no Bairro no afastamento de estudo para a realização de doutorado no exterior da Profa Janaina e ao Edital do Governo Brasileiro.

\section{REFERÊNCIAS}

ABIB, J. A. D. Teoria Moral de Skinner e Desenvolvimento Humano. Cidade: Psicologia - Reflexão Crítica, 14, 2001.

CARMI, Elio. Branding. Una visione Design Oriented.Bologna: Logo Fausto Lupetti Editore, 2011.

CHAFFEE, J. Pense diferente, viva criativamente: Oito passos para tornar a sua vida mais completa. Rio de Janeiro: Campus, 2000.

CHUSTER \& COLS. Objetivo Psicanalítico: Fundamentos de uma mudança de paradigma da Psicanálise. Porto Alegre: 1a Edição do Autor, 2011.

DORNELAS, José Carlos Assis. Empreendedorismo: Transformando Idéias em Negócios. Rio de Janeiro: Elsevier, 2001.

DRUCKER, Peter. F. O Gerente Eficaz. São Paulo: Editora Zahar, 1974.

EYSENCK, H. J. As formas de medir a criatividade. Em: M. A. Boden (Org.), Dimensões da criatividade (pp. 203-244). Porto Alegre: Artes Médicas, 1999.

GIACOBONE, Tersilla F., GALLICO, Dalia. ADI Design Codex Lombardia 001: II paesaggio dell'innovazione. Milano e la Lombardia. ADI (ADI Associazione per il Disegno Industriale. Bologna: Logo Fausto Lupetti Editore, 2010.

LEGRENZI, Paolo. Creatività e innovazione. Bologna: II Mulino, 2005.

LUBART, T. Psicologia da Criatividade. Porto Alegre: Artmed, 2007.

MEDEIROS, D. C. Técnica SMART - Brasil, 2014. Disponível na internet por HTTP em: <http://wglucchesi.blogspot.com.br/2013/05/artigo-estruturando-seus-objetivosou.html>. Acesso em 30 abr. 2014.

MOZZER, G. N. S; BORGES, F. T. A Criatividade infantil na perspectiva de Levvigotski. Revista da Faculdade de Educação da UFG v. 33, n. 2 (2008). Disponível em: <http://www.revistas.ufg.br>. Acesso em 12 maio. 2014. 
MURARI, Silvia Cristiane; HENKLAIN, Marcelo Henrique Oliveira. Criatividade em debate: algumas contribuições da análise do comportamento. Creativity in focus: some contributions of the analysis of behavior. Temas psicol., Ribeirão Preto , v. 21, n. 1, jun. 2013.

PODER além da vida. Direção: Victor Salva, Shalimar Reodica, produtor, EUA, Focus Filmes, 2006.

PORTA em Porta, De. Direção: Steven Schachter, EUA,Turner Network Television (TNT), 2002.

TESTORE, Giulia. Ergonomia e Creativita: utente e non intentional design. Milano: Maggioli Editore, 2009.

ZENO Cardoso; NUNES, Rui Cardoso. Dicionário de Regionalismos do Rio Grande do Sul. Porto Alegre: Martins Livreiro, 2009, 12a edição. 